\title{
Preparation of Multiwalled Carbon Nanotubes/Hydroxyl-Terminated Silicone Oil Fiber and Its Application to Analysis of Crude Oils
}

\author{
Shukui Zhu, ${ }^{1,2}$ Ting Tong, ${ }^{1,2}$ Wanfeng Zhang, ${ }^{1,2}$ Wei Dai,, ${ }^{1,2}$ Sheng He, \\ Zhenyang Chang, ${ }^{1,2}$ and Xuanbo Gao ${ }^{1,2}$ \\ ${ }^{1}$ Key Laboratory of Tectonics and Petroleum Resources of Ministry of Education, China University of Geosciences, \\ Wuhan 430074, China \\ ${ }^{2}$ Faculty of Earth Resources, China University of Geosciences, 388 Lumo Road, Wuhan 430074, China \\ Correspondence should be addressed to Shukui Zhu; shukuizhu@126.com
}

Received 31 August 2013; Accepted 22 October 2013; Published 22 January 2014

Academic Editors: M. B. Amran, T. G. Strein, and R. Zakrzewski

Copyright (c) 2014 Shukui Zhu et al. This is an open access article distributed under the Creative Commons Attribution License, which permits unrestricted use, distribution, and reproduction in any medium, provided the original work is properly cited.

\begin{abstract}
A simple and efficient method to analyze the volatile and semivolatile organic compounds in crude oils has been developed based on direct immersion solid-phase microextraction coupled to comprehensive two-dimensional gas chromatography/time-of-flight mass spectrometry (DI-SPME-GC $\times$ GC/TOFMS). A novel fiber, multiwalled carbon nanotubes/hydroxyl-terminated silicone oil (MWNTs-TSO-OH), was prepared by sol-gel technology. Using standard solutions, the extraction conditions were optimized such as extraction mode, extraction temperature, extraction time, and salts effect. With the optimized conditions, a real crude oil sample was extracted and then analyzed in detail. It shows that the proposed method is very effective in simultaneously analyzing the normal and branched alkanes, cycloalkanes, aromatic hydrocarbons, and biomarkers of crude oil such as steranes and terpanes. Furthermore, the method showed good linearity $(r>0.999)$, precision (RSD $<8 \%$ ), and detection limits ranging from 0.2 to $1.6 \mathrm{ng} / \mathrm{L}$.
\end{abstract}

\section{Introduction}

As the major components in crude oils, volatile and semivolatile organic compounds have played important roles during petroleum exploration and development. Among the various classes of compounds in crude oil, some biomarkers such as terpanes and steranes are considered as the unique fingerprint of a specific oil and used to determine petroleum system characteristics such as origin, thermal maturity, and biodegradation level, as well as oil-oil and oil-source rock correlations [1]. At the same time, these molecules are also excellent indicators for tracing degree of weathering and the fate of spilled oil in the environment, due to their resistance to petrochemical and microbial degradation. Therefore, the qualitative and quantitative determination of volatile and semivolatile organic compounds in crude oil has attracted increasing attention.

Most existing analytical methods used to determine these organic compounds in crude oil are conventional one-dimensional gas chromatography coupled to mass spectrometry (1DGC/MS) or tandem mass spectrometry (GC/MS/MS) [2-4]. However, crude oils are complex matrices and consist of thousands of compounds, so the peak capacity of 1DGC is insufficient and peaks overlap seriously $[5,6]$. In order to overcome these deficiencies, some laborintensive and time-consuming sample preparation steps have to be used before GC analysis. The routine method is column chromatography on silica gel and alumina, by which crude oils are separated into different fractions such as saturated hydrocarbon fraction, aromatic fraction, and polar fraction [7]. The separated fractions are further concentrated and then injected to GC for analysis. During the sample preparation, large amounts of high-purity organic solvents that are potentially toxic and expensive are used. Additionally, manual concentration steps are usually conducted by vaporizing each collected fraction under nitrogen flow, which easily results in the loss of some light components. In order to obtain more accurate and efficient analysis of crude oils, some 
novel methods of sample pretreatment and chromatographic separation are quite required.

Solid-phase microextraction (SPME) is a simple, timesaving, solvent-free, low-cost, and efficient extraction technique, which integrates the extraction, preconcentration, and sample injection into one step [8]. It has gained widespread acceptance in the recent years and has been successfully applied to the extraction and enrichment of trace components in different sample matrices such as foods [9], environmental water or soils [10-12], and natural products $[13,14]$. Sampling of analytes is done either through direct immersion of suitable fiber into a liquid phase (DI-SPME) or in headspace (HS-SPME), followed by thermal desorption of the extracted analytes in the hot injection port of GC [15]. However, as a promising method of sample pretreatment, only a few applications in the crude oils were reported and mainly focused on analysis of some special compounds or matrices, such as petroleum hydrocarbons in soils [16], methanol [17], and compounds with volatility less than nPentadecane $\left(\mathrm{C}_{15}\right)$ [18] in the crude oils. Up to now, we are not aware of any report on the application of SPME in semivolatile compounds of crude oils, especially like petroleum biomarkers such as terpanes and steranes. The possible reason is as follows. Firstly, the maximum operating temperature of the existing commercial SPME fibers is no more than $280^{\circ} \mathrm{C}$ (except polyacrylate), which is relatively low when comparing with eluting temperature of these compounds. Secondly, the surface area or adsorption capacity of commercial fibers is low for complex composition of crude oil samples, which results in the low sensitivity of trace petroleum biomarkers. Thirdly, commercial SPME fibers are designed to extract either polar or nonpolar analytes from a given matrix, which is not suitable for crude oils comprising different chemical classes. Fourthly, thermal and solvent restrictions are encountered with traditional SPME fibers because the majority of these fibers are prepared by mere physical deposition of the polymer coating on the substrate of the fused-silica fiber [19].

In order to overcome the above shortages, a novel SPME coating made from multiwalled carbon nanotubes (MWNTs) and hydroxyl-terminated silicone oil (TSO-OH) was prepared by sol-gel technique in this study. Sol-gel technique can create surface-bonded SPME coatings with porous structure and good thermal stability. MWNTs have strong physical adsorption ability to hydrophobic organic compounds, good thermal, mechanical, and chemical stability, and high surface-to-volume ratio, and so forth. Based on the homemade SPME fiber, the volatile and semivolatile organic compounds in crude oils were extracted in DI-SPME mode and then analyzed by comprehensive two-dimensional gas chromatography coupled with time-of-flight mass spectrometry $(\mathrm{GC} \times \mathrm{GC} / \mathrm{TOFMS})$. The extraction temperature, extraction time, salts effect, volume of water added into the sample, and solvents addition were discussed in detail by using standard solutions. The individual components in crude oils were well separated and identified, such as normal and branched alkanes, acyclic isoprenoids, aromatic hydrocarbons, and polycyclic terpanes and steranes. Additionally, an accurate quantitative method was developed for the determination of some important petroleum biomarkers like polycyclic terpanes and steranes and so forth.

\section{Experimental}

2.1. Instrumentation. The GC $\times$ GC system consisted of a GC (7890A model, Agilent Technologies, Wilmington, DE, USA) equipped with a flame ionization detector (FID) and a timeof-flight mass spectrometer (Pegasus 4D, Leco Corp., St. Joseph, MI, USA). The dual-stage, quad-jet thermal modulator was used, and a detailed description of the modulator has been given in a previous publication [20]. The SPME devices were purchased from Supelco (Bellefonte, PA, USA).

DI-SPME-GC $\times$ GC/TOFMS analysis was performed using a DB-Petro column $(50 \mathrm{~m} \times 0.20 \mathrm{~mm} \times 0.50 \mu \mathrm{m})$ as the 1st column and a DB-17Ht column $(1.5 \mathrm{~m} \times 0.10 \mathrm{~mm} \times$ $0.10 \mu \mathrm{m}$ ) as the 2 nd column, both of which were from J\&W Scientific (Folsom, CA, USA). The carrier gas was helium (purity $\geq 99.9995 \%$ ) with a flow rate of $1.0 \mathrm{~mL} / \mathrm{min}$. The injector temperature was $300^{\circ} \mathrm{C}$. The 1 st oven temperature program was as follows: $40^{\circ} \mathrm{C}$ for $1 \mathrm{~min}, 3^{\circ} \mathrm{C} / \mathrm{min}$ to $300^{\circ} \mathrm{C}$, hold for $30 \mathrm{~min}$. The 2 nd oven temperature was $10^{\circ} \mathrm{C}$ above the 1st oven. Modulation was carried out using a $15^{\circ} \mathrm{C}$ temperature offset and an $8 \mathrm{~s}$ modulation time (hot pulse $2 \mathrm{~s}$ ). The mass spectrometer was operated at an acquisition rate of 100 spectra per second for a mass range of 50 to $550 \mathrm{u}$, using $70 \mathrm{eV}$ electron impact ionization and $1500 \mathrm{~V}$ multichannel plate voltage. The ion-source temperature was $220^{\circ} \mathrm{C}$ and the transfer-line temperature was $300^{\circ} \mathrm{C}$. The pressure inside the flight tube was $1.1 \times 10^{-7}$ Torr.

To mix various solution ingredients thoroughly, an Ultrasonicator model KQ-50DE (Kunsan Ultrasonicator Instrument Corporation, Kunsan, China) was used. A centrifuge model TGL-16C (Shanghai Anting Instrument Factory, Shanghai, China) was used to separate the sol solution from the precipitate during fiber preparation. A magnetic stirrer DF-101B (Leqing, China) was used for stirring the sample during extraction.

2.2. Reagents and Materials. The MWNTs with purity $95 \%$ were purchased from Shenzhen Nanotech Port (Shenzhen, China). TSO-OH was purchased from Aldrich (Allentown, PA, USA). Tetraethoxysilane (TEOS) and poly(methylhydrosiloxane) (PMHS) were obtained from the chemical plant of Wuhan University (Wuhan, China). Trifluoroacetic acid (TFA) was purchased from Merck, Germany. The fusedsilica fiber $(120 \mu \mathrm{m}$, o.d.) with protective polyimide coating was provided by Academy of Post and Telecommunication, Wuhan, China.

Custom standard mixtures $\left(0.5 \mathrm{mg} / \mathrm{mL}\right.$ for each) are $\mathrm{C}_{8}-$ $\mathrm{C}_{40} n$-alkanes (Accustandard), 16 polycyclic aromatic hydrocarbons (PAHs, Accustandard). The 16 PAHs $(0.2 \mathrm{mg} / \mathrm{mL}$ for each) are naphthalene $\left(\mathrm{C}_{10} \mathrm{H}_{8}\right)$, acenaphthylene $\left(\mathrm{C}_{12} \mathrm{H}_{8}\right)$, acenaphthene $\left(\mathrm{C}_{12} \mathrm{H}_{10}\right)$, fluorene $\left(\mathrm{C}_{13} \mathrm{H}_{10}\right)$, phenanthrene $\left(\mathrm{C}_{14} \mathrm{H}_{10}\right)$, anthracene $\left(\mathrm{C}_{14} \mathrm{H}_{10}\right)$, fluoranthene $\left(\mathrm{C}_{16} \mathrm{H}_{10}\right)$, pyrene $\left(\mathrm{C}_{16} \mathrm{H}_{10}\right)$, benzo[a]anthracene $\left(\mathrm{C}_{18} \mathrm{H}_{12}\right)$, Chrysene $\left(\mathrm{C}_{18} \mathrm{H}_{12}\right)$, benzo[b]fluoranthene $\left(\mathrm{C}_{20} \mathrm{H}_{12}\right)$, benzo[k]fluoranthene $\left(\mathrm{C}_{20} \mathrm{H}_{12}\right)$, benzo[a]pyrene $\left(\mathrm{C}_{20} \mathrm{H}_{12}\right)$, indeno[1,2,3-cd] pyrene $\left(\mathrm{C}_{22} \mathrm{H}_{12}\right)$, dibenz[a,h]anthracene $\left(\mathrm{C}_{22} \mathrm{H}_{14}\right)$, and 
benzo[g,h,i]perylene $\left(\mathrm{C}_{22} \mathrm{H}_{12}\right)$. These compounds were used as external standards for compound identification and external quantification. 5 - $\alpha$-Androstane (Accustandard) was used as internal standards for quantification of terpanes and steranes.

2.3. Synthesis of MWNTs-TSO-OH. According to the literature [21], MWNTs were first refluxed in $2.6 \mathrm{M}$ nitric acid for $45 \mathrm{~h}$, oxidized by sulfuric acid (98\%)/nitric acid (70\%) for $24 \mathrm{~h}$, and then stirred in $\mathrm{SOCl}_{2}$ at $70^{\circ} \mathrm{C}$ for $24 \mathrm{~h}$. The product was thoroughly mixed with TSO-OH in a flask, heated to $75^{\circ} \mathrm{C}$, and vigorously stirred under nitrogen protection for $48 \mathrm{~h}$. The reaction mixture was dissolved in dichloromethane and filtered using a $0.2 \mu \mathrm{m}$ PTFE film. Ethanol was added to the filtrate and a black precipitate was obtained and proved to be MWNTs-TSO-OH.

2.4. Fiber Preparation. Prior to sol-gel coating, the $6 \mathrm{~cm}$ long fused-silica fiber was dipped in acetone for $3 \mathrm{~h}$ to remove the protective polyimide layer, in a $1 \mathrm{M} \mathrm{NaOH}$ solution for $1 \mathrm{~h}$ to expose the maximum number of silanol groups on the surface, cleaned with water, and dipped in $0.1 \mathrm{M} \mathrm{HCl}$ solution for 30 min to neutralize the excess $\mathrm{NaOH}$, cleaned again with water and air-dried at room temperature.

A sol solution was prepared by dissolving $90 \mathrm{mg}$ of MWNTs-TSO-OH, $200 \mu \mathrm{L}$ of TEOS, $55 \mu \mathrm{L}$ of TSO-OH, $10 \mathrm{mg}$ of PMHS, and $180 \mu \mathrm{L}$ of TFA $\left(5 \% \mathrm{H}_{2} \mathrm{O}\right)$ in $300 \mu \mathrm{L}$ of dichloromethane. The mixture was then mixed thoroughly by ultrasonic agitation for $5 \mathrm{~min}$, centrifuged at $8000 \mathrm{rpm}$ for $8 \mathrm{~min}$, and the clear supernatant of the sol solution was transferred to another clean vial for fiber coating. The treated fiber was dipped vertically into the sol solution and held for $5 \mathrm{~min}$, and then the fiber was drawn out of the sol solution, until a sol-gel coating was formed on the outer surface of the fiber end (about $1 \mathrm{~cm}$ ). The coating process was repeated several times in the same sol solution until the desired thickness of the coating was obtained $(70 \mu \mathrm{m}$ in this study). The fiber was irradiated under ultraviolet light for $30 \mathrm{~min}$ and then placed in a desiccator at room temperature for $24 \mathrm{~h}$. The fiber was conditioned as follows: initially placed in a GC injection port at a $100^{\circ} \mathrm{C}$ with a gentle $\mathrm{N} 2$ flow for $1 \mathrm{~h}$ and then conditioned again at $220-340^{\circ} \mathrm{C}$ for $2 \mathrm{~h}$.

2.5. Preparation of Working Standards and Samples. Compound identification and external quantification for the $n$ alkanes and PAHs were conducted through injections of two custom standard solutions, one containing $\mathrm{C}_{8}-\mathrm{C}_{40} n$-alkanes and another containing a range of two to six ring PAHs. These standards were injected separately. $\mathrm{C}_{8}-\mathrm{C}_{40}$ standard solution was prepared in $n$-hexane at concentrations of 5,10 , $20,50,100,200,500$, and $800 \mu \mathrm{g} / \mathrm{L}$. PAHs standard solution was prepared in $n$-hexane at concentrations of $2,5,10,20$, $50,100,200$, and $500 \mu \mathrm{g} / \mathrm{L}$. For $\mathrm{C}_{8}-\mathrm{C}_{40}$ and PAHs standard solutions, $15 \mu \mathrm{L}$ of each was diluted with $15 \mathrm{~mL}$ of doubly deionized water, respectively. The final concentrations of $\mathrm{C}_{8}-$ $\mathrm{C}_{40}$ working solution were $5,10,20,50,100,200,500$, and $800 \mathrm{ng} / \mathrm{L}$. The final concentrations of PAHs working solution were $2,5,10,20,50,100,200$, and $500 \mathrm{ng} / \mathrm{L}$. A standard solution of internal standard was prepared in $n$-hexane to yield $20 \mathrm{mg} / \mathrm{mL}$ of $5-\alpha$-Androstane. All solutions were stored at $-20^{\circ} \mathrm{C}$ before use.

$0.1 \mathrm{~g}$ of crude oil sample was dissolved in $50 \mathrm{~mL}$ of $\mathrm{n}$ hexane and then dispersed by ultrasonic treatment for $5 \mathrm{~min}$. After overnight stand, the solution was added into a funnel for filtering asphaltenes. The asphaltenes on the absorbent cotton were further rinsed by $\mathrm{n}$-hexane for 3 times. All the filtrates were collected and concentrated to $2 \mathrm{~mL}$ by rotatable vacuum evaporator at $40^{\circ} \mathrm{C} .10 \mu \mathrm{L}$ of concentrated sample was diluted with $15 \mathrm{~mL}$ of doubly deionized water.

2.6. DI-SPME Procedure. To obtain high extraction efficiency for the semivolatile compounds, DI-SPME was used. For each SPME analysis, $15 \mathrm{~mL}$ of standard solution or sample solution was placed into a $20 \mathrm{~mL}$ glass vial with $5 \mathrm{~g}$ of $\mathrm{NaCl}$ and a magnetic stir bar. The vial was tightly capped with a butyl rubber stopper wrapped with PTFE sealing tape and an aluminum cap. Then the stainless steel needle, where the fiber is housed, was pushed through the vial septum, and then the fiber was pushed out of the housing and immersed into the sample for $30 \mathrm{~min}$ at $70^{\circ} \mathrm{C}$. After extraction, the fiber was removed from the sample vial and immediately inserted into the $\mathrm{GC} \times \mathrm{GC}$ injector port at $300^{\circ} \mathrm{C}$ with $5 \mathrm{~min}$ desorption time. Blank runs were performed before sampling to eliminate any carry-over of analytes from the previous extraction.

\section{Results and Discussion}

\subsection{Characteristics of MWNTs-TSO-OH Fiber}

3.1.1. Thermal Stability and Lifespan of the Coating. As an important parameter of SPME fiber, the thermal stability was investigated by performing extraction of $n$-alkanes and PAHs standard solutions after the fiber is being exposed at the GC injector port for $1 \mathrm{~h}$ at $280,300,320$, and $340^{\circ} \mathrm{C}$, respectively. Figure 1 shows the peak areas of 4 representative compounds $\left(n \mathrm{C}_{17}\right.$-alkane, pristine, naphthalene, and 5- $\alpha$-Androstane) at different injector temperatures. It can be seen that the fiber exhibits excellent thermal stability up to $340^{\circ} \mathrm{C}$ without loss of extraction efficiency (peak area). Enhanced thermal stability allowed the use of higher injector temperatures for efficient desorption of semivolatile analytes, which contributes to the analysis of extended range of analytes including the highboiling-point terpanes and steranes.

Under the high temperature along with long extraction time, the MWNTs-TSO-OH coating's extraction efficiency was monitored after it had been used for 50, 80, and 100 adsorption/desorption times. Due to the special nature of MWNTs and the strong chemical bonding provided by solgel technology, no obvious decline was observed after it had been used for 100 times.

3.1.2. Preparation Reproducibility. Ten MWNTs-TSO-OH fibers (five prepared within a batch and five in different batches) with $70 \mu \mathrm{m}$ fiber thickness were used to evaluate the fibers' preparation reproducibility. The extractions of $n$ alkanes and PAHs standard solutions were performed in 


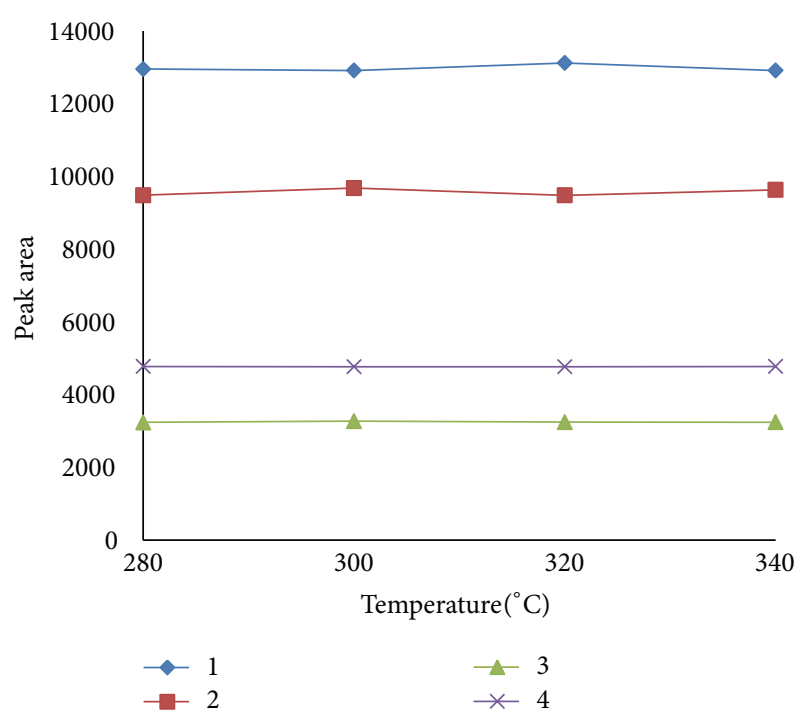

Figure 1: Thermal stability of MWNTs-TSO-OH fiber. Conditions: extraction time, $30 \mathrm{~min}$; extraction temperature, $70^{\circ} \mathrm{C}$; and desorption time, 5 min. Peaks: $1, n \mathrm{C}_{17}$-alkane; 2, pristine; 3 , naphthalene; and 4, 5- $\alpha$-Androstane.

TABLE 1: Preparation reproducibility of MWNTs-TSO-OH fibers with $70 \mu \mathrm{m}$ thickness.

\begin{tabular}{lcc}
\hline Compounds & \multicolumn{2}{c}{ RSD $^{\mathrm{a}}(\%)$} \\
\hline$n \mathrm{C}_{17}$-alkane & 1.21 & 2.86 \\
Pristine & 3.50 & 5.18 \\
Naphthalene & 5.27 & 8.12 \\
$5-\alpha$-Androstane & 4.63 & 8.39 \\
\hline
\end{tabular}

${ }^{a}$ RSD: relative standard deviation, calculated according to the peak areas.

the same condition, and the peak areas of 4 representative compounds $\left(n \mathrm{C}_{17}\right.$-alkane, pristine, naphthalene, and 5- $\alpha$ Androstane) were selected to compare. Table 1 shows that the relative standard deviation (RSD) of peak areas is less than $6 \%$ within a batch and $9 \%$ in different batches, respectively. Apparently, the sol-gel MWNTs-TSO-OH fibers have good reproducibility and are suitable for the accurate quantitative analysis of volatile and semivolatile compounds in crude oils.

3.2. Optimization of SPME Procedures. Figure 2 shows the extraction capability of the sol-gel coated MWNTs-TSO-OH fiber in DI-SPME mode and HS-SPME mode with the $\mathrm{C}_{8}-$ $\mathrm{C}_{40}$ standard solution. It can be seen that HS-SPME exhibited high extraction efficiency for volatile compounds but failed within the range of $\mathrm{C}_{17}-\mathrm{C}_{40}$. On the contrary, DI-SPME allowed satisfactory results almost in the whole range of carbon number, especially for the semivolatile compounds. In order to obtain high sensitivity of some semivolatile biomarkers at trace level, DI-SPME mode was selected in this study.

Figure 3 shows the extraction temperature profile for 4 representative compounds $\left(n \mathrm{C}_{17}\right.$-alkane, pristine, naphthalene, and 5- $\alpha$-Androstane). Except for naphthalene, the extraction yield increased with an increase in temperature. In order to obtain high extraction efficiency for most volatile and semivolatile compounds, $70^{\circ} \mathrm{C}$ was selected as the optimum extraction temperature.

The extraction times of 4 representative compounds $\left(n \mathrm{C}_{17}\right.$-alkane, pristine, naphthalene, and 5 - $\alpha$-Androstane) were investigated from 10 to $60 \mathrm{~min}$ at $70^{\circ} \mathrm{C}$ (Figure 4). The responses of 4 compounds increased with the increase of extraction time, and the equilibrium could not be achieved. Due to the porous structure of the sol-gel MWNTs-TSO-OH coating, the analytes were extracted mainly by adsorption interaction, where a competitive process happened and the best extraction efficiency was not at the point of equilibrium [21]. Considering the sensitivity and time efficiency, $30 \mathrm{~min}$ was selected as the optimum extraction time in this study.

Salt effect is usually used to increase the extraction efficiency of analytes in SPME. Figure 5 shows the effect of salt $(\mathrm{NaCl})$ on the extraction of 4 representative compounds $\left(n \mathrm{C}_{17}\right.$-alkane, pristine, naphthalene, and 5- $\alpha$-Androstane). An obvious increase of peak area was observed with the increase of salt concentration. Apparently, increase of ion strength is beneficial to the transfer of analytes from solution to MWNTs-TSO-OH coating. Therefore, $5 \mathrm{~g} \mathrm{NaCl}$ was added into each standard solution or sample solution in this study.

\subsection{Characterization of Components in a Real Crude Oil} Sample by DI-SPME-GC $\times$ GC/TOFMS. Analysis of a real crude oil sample from an oil field in China was performed by DI-SPME-GC $\times$ GC/TOFMS using the optimized conditions. The total ion current chromatogram is shown in Figure 6. Owing to the different interaction of compounds towards the stationary phase, the apparent group type separation can be observed. The $2 \mathrm{D}$ plane is divided into four separated zones according to the class of compounds: normal and branched alkanes, cycloalkanes, aromatic hydrocarbons, and biomarkers of crude oil such as steranes and terpanes. By combining the automated data processing of TOFMS software, the ordered GC $\times$ GC chromatogram, and the retention index database developed by our group, compounds in the oil sample were identified in detail. The detailed information and availability of the retention index database have been described in a previous publication [22].

3.3.1. Paraffins and Naphthenes. The normal and branched alkanes are located at the bottom of the 2D plane, and branched alkanes tend to occupy the lower part with the number of carbon atom increasing. Additionally, some acyclic isoprenoids are also included in this region and clearly visible as resolved peaks. The cycloalkanes are located at upper part compared with saturated hydrocarbons. Within the cycloalkanes, individual compounds are clearly resolved, and apparent roof-tile effect is observed. Compounds regularly distribute along oblique lines according to the degree of branching and number of alkyl-substituents attached to the cyclic group, which are ultimately identified as the branched cyclopentane and cyclohexane isomers. Some important paraffins and naphthenes are marked in Figure 6 and listed in Table 2. 


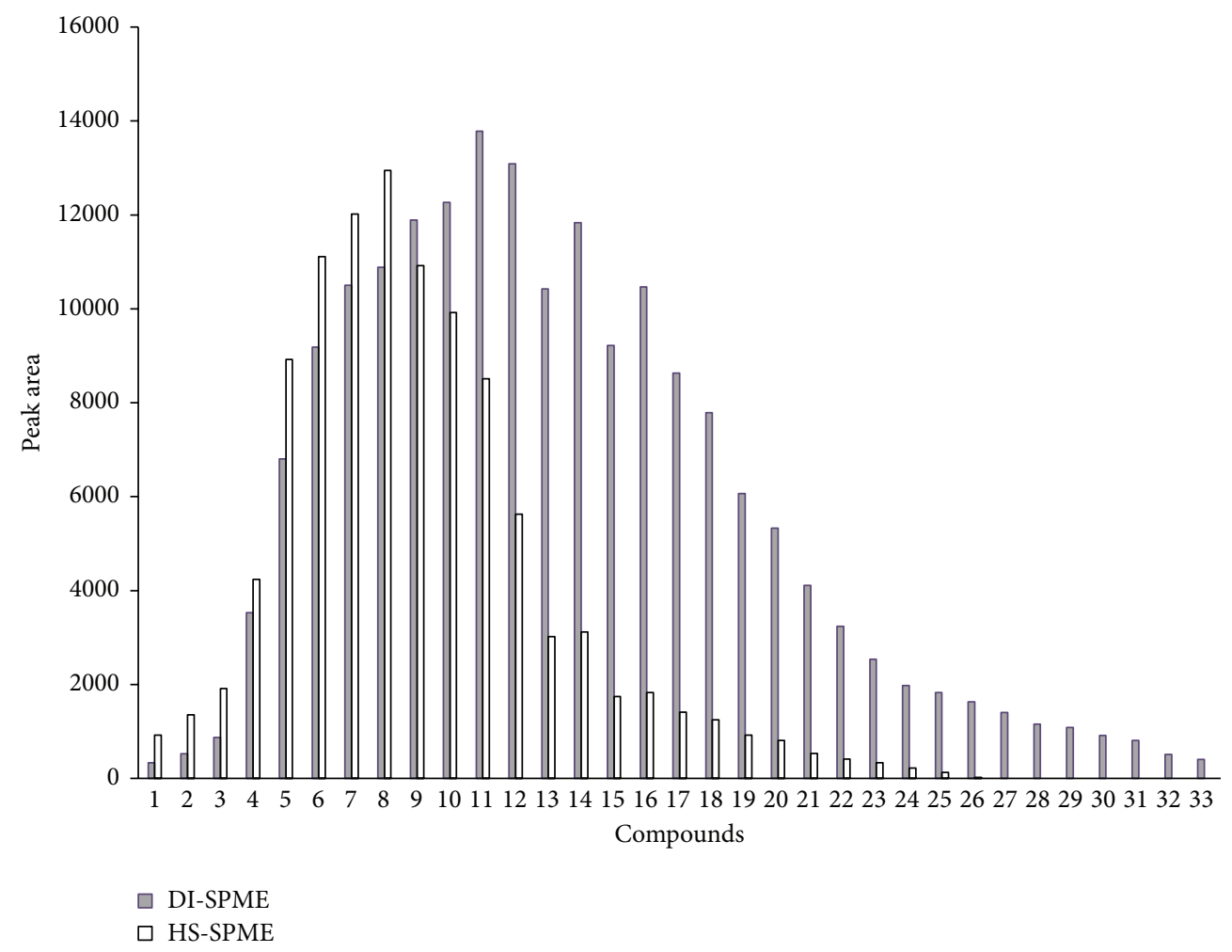

FIgURE 2: The extraction capability of the sol-gel coated MWNTs-TSO-OH fiber in DI-SPME mode and HS-SPME mode with the $\mathrm{C}_{8}-$ $\mathrm{C}_{40}$ standard solution. Peaks: 1, n-octane; 2, n-nonane; 3, n-decane; 4, n-undecane; 5, n-dodecane; 6, n-tridecane; 7, n-tetradecane; 8 , npentadecane; 9, n-hexadecane; 10, n-heptadecane; 11, n-octadecane; 12, n-nonadecane; 13, n-eicosane; 14, n-heneicosane; 15, n-docosane; 16, n-tricosane; $17, n$-tetracosane; 18 , n-pentacosane; $19, n$-hexacosane; 20, n-heptacosane; $21, n$-octacosane; $22, n$-nonacosane; 23 , n-triacontane; 24, n-hentriacontane; 25, n-dotriacontane; 26, n-tritriacontane; 27, n-tetratriacontane; 28, n-pentatriacontane; 29, n-hexatriacontane; 30, nheptatriacontane; 31, n-octatriacontane; 32, n-nonatriacontane; and 33, n-tetracontane.

3.3.2. Aromatic Hydrocarbons. It can be seen from Figure 6 that GC $\times$ GC completely separates the aromatic hydrocarbons from paraffins and naphthenes and shows all of them in the same chromatogram, which cannot be obtained in 1DGC analysis owing to the serious overlap of peaks and the lower amount of aromatic hydrocarbons relative to saturated hydrocarbons. Compared with paraffins and naphthenes, aromatic hydrocarbons are located at the upper part of the $2 \mathrm{D}$ plane because of their higher polarity. In the second dimension, compounds elute in proper order from mono-, di-, to triaromatic hydrocarbons. Isomers are grouped into the same band of the chromatogram and can be recognized owing to the roof-tile effect. The different groups are marked in Figure 6(a), and the identification of some important compounds is listed in Table 2.

3.3.3. Biomarkers of Crude Oil. Polycyclic terpanes and steranes are the widely used biomarkers in petroleum geochemistry, owing to their general resistance to weathering, biodegradation, evaporation and other processes. They can be used by geologists to interpret the characteristics of petroleum source rocks when only oil samples are available. Additionally, they can also provide some important information on the organic matter in the source rock and environmental conditions during its deposition and burial, the thermal maturity experienced by rock or oil, the degree of biodegradation, and some aspects of source rock mineralogy and age [1]. But in high mature, over mature oil or source rock, they are usually difficult to be identified owing to their quite low content. In this study, the polycyclic terpanes and steranes are clearly resolved and identified using DI-SPMEGC $\times$ GC/TOFMS. In Figure 6(b), the blowup of the marked region shows the GC $\times$ GC separation of polycyclic terpanes and steranes. Compared with traditional 1DGC/MS methods, better separation is obtained and more trace components are identified. The identification of marked peaks is listed in Table 3. It can be seen from Figure 6(b) and Table 3 that abundant tri- and tetracyclic diterpanes appear in the crude oil, steranes show a low proportion to triterpanes, and $\mathrm{C}_{29}$ steranes predominate over $\mathrm{C}_{27}$ and $\mathrm{C}_{28}$ homologs.

3.4. Quantitative Calibration and Reproducibility. Based on the sol-gel MWNTs-TSO-OH coating, a series of experiments were performed to validate the DI-SPME-GC $\times$ GC/TOFMS analysis of volatile and semivolatile compounds in crude oils. Table 4 summarizes the precision, limits of detection (LODs), and linearity ranges of the proposed method. The precision of the method was expressed as the relative standard deviation (RSD) and determined by analysis of standard solutions in five times. The values obtained were all below 
TABLE 2: Identification of some important paraffins, naphthens, and aromatic hydrocarbons.

\begin{tabular}{|c|c|c|c|c|c|c|c|}
\hline${ }^{1} t_{R}$ & ${ }^{2} t_{R}$ & Compounds & Family & ${ }^{1} t_{R}$ & ${ }^{2} t_{R}$ & Compounds & Family \\
\hline 3.17 & 2.06 & Toluene & $1 \mathrm{~A}$ & 42.75 & 6.42 & 4-Methyldibenzofuran & $2 \mathrm{~A}$ \\
\hline 4.50 & 2.28 & 1,3-Dimethyl benzene & $1 \mathrm{~A}$ & 43.33 & 6.06 & Ethylbiphenyl & $2 \mathrm{~A}$ \\
\hline 4.50 & 2.31 & 1,2-Dimethyl benzene & $1 \mathrm{~A}$ & 43.42 & 6.34 & 2-Methyldibenzofuran & $2 \mathrm{~A}$ \\
\hline 4.58 & 2.34 & Ethyl benzene & $1 \mathrm{~A}$ & 43.92 & 6.69 & 3-Methyldibenzofuran & $2 \mathrm{~A}$ \\
\hline 4.75 & 2.35 & 1,4-Dimethyl benzene & $1 \mathrm{~A}$ & 44.42 & 5.58 & 1,3,5,7-Tetramethylnaphthalene & $2 \mathrm{~A}$ \\
\hline 4.92 & 1.79 & 1,2,3-Trimethyl cyclohexane & $\mathrm{PN}$ & 45.58 & 5.55 & 1,3,6,7-Tetramethylnaphthalene & $2 \mathrm{~A}$ \\
\hline 5.08 & 1.85 & 1-Ethyl-4-methyl cyclohexane & $\mathrm{PN}$ & 46.42 & 5.82 & 1,4,6,7-Tetramethylnaphthalene & $2 \mathrm{~A}$ \\
\hline 5.17 & 1.96 & 1-Propyl cyclohexane & $\mathrm{PN}$ & 46.58 & 5.86 & 1,2,5,7-Tetramethylnaphthalene & $2 \mathrm{~A}$ \\
\hline 5.33 & 1.84 & 1,1,3,5-Tetramethylcyclohexane & $\mathrm{PN}$ & 46.75 & 6.43 & 2-Methylfluorene & $2 \mathrm{~A}$ \\
\hline 5.92 & 2.64 & 1-Methylethyl benzene & $1 \mathrm{~A}$ & 46.92 & 5.60 & 2,3,6,7-Tetramethylnaphthalene & $2 \mathrm{~A}$ \\
\hline 6.00 & 2.12 & 1-Ethyl-3-methyl cyclohexane & $\mathrm{PN}$ & 47.17 & 6.69 & 1-Methylfluorene & $2 \mathrm{~A}$ \\
\hline 6.08 & 2.08 & 1-Ethyl-2-methyl cyclohexane & $\mathrm{PN}$ & 47.50 & 5.92 & 1,2,6,7-Tetramethylnaphthalene & $2 \mathrm{~A}$ \\
\hline 6.50 & 1.91 & 1,2,3,5-Tetramethylcyclohexane & $\mathrm{PN}$ & 47.67 & 6.02 & 1,2,3,7-Tetramethylnaphthalene & $2 \mathrm{~A}$ \\
\hline 6.83 & 2.80 & Propyl benzene & $1 \mathrm{~A}$ & 47.75 & 6.99 & 3-Methylfluorene & $2 \mathrm{~A}$ \\
\hline 7.08 & 2.79 & 1-Ethyl-4-methyl benzene & $1 \mathrm{~A}$ & 47.92 & 6.00 & 1,2,3,6-Tetramethylnaphthalene & $2 \mathrm{~A}$ \\
\hline 7.08 & 2.87 & 1-Ethyl-3-methyl benzene & $1 \mathrm{~A}$ & 47.92 & 2.74 & n-Heptadecane & $\mathrm{PN}$ \\
\hline 7.17 & 2.90 & 1,2,3-Trimethyl benzene & $1 \mathrm{~A}$ & 48.25 & 2.61 & Pristane & $\mathrm{PN}$ \\
\hline 7.33 & 2.85 & 1,2,4-Trimethyl benzene & $1 \mathrm{~A}$ & 48.75 & 6.22 & 1,2,5,6-Tetramethylnaphthalene & $2 \mathrm{~A}$ \\
\hline 7.67 & 2.03 & 1-Ethyl-1,3-dimethylcyclohexane & $\mathrm{PN}$ & 49.42 & 7.92 & Dibenzothiophene & $2 \mathrm{~A}$ \\
\hline 7.75 & 2.94 & 1-Ethyl-2-methyl benzene & $1 \mathrm{~A}$ & 50.83 & 7.90 & Phenanthrene & $3 \mathrm{~A}$ \\
\hline 7.83 & 2.09 & 1-Tethyl-2-propyl cyclohexane & $\mathrm{PN}$ & 52.67 & 6.21 & 2-Ethylfluorene & $2 \mathrm{~A}$ \\
\hline 7.83 & 2.04 & 1,1,3,4-Tetramethyl cyclopentane & $\mathrm{PN}$ & 52.92 & 6.37 & 3,6-Dimethylfluorene & $2 \mathrm{~A}$ \\
\hline 8.00 & 2.04 & 1,1,3,3,5-Pentamethylcyclohexane & $\mathrm{PN}$ & 53.08 & 2.75 & n-Octadecane & $\mathrm{PN}$ \\
\hline 8.08 & 2.05 & 1,5-Diethyl-2,3-dimethylcyclohexane & $\mathrm{PN}$ & 53.25 & 6.43 & 1-Ethylfluorene & $2 \mathrm{~A}$ \\
\hline 8.33 & 1.95 & n-Decane & $\mathrm{PN}$ & 53.50 & 6.54 & 2,6-Dimethylfluorene & $2 \mathrm{~A}$ \\
\hline 8.33 & 2.08 & Ethyl propyl cyclopentane & $\mathrm{PN}$ & 53.83 & 2.69 & Phytane & $\mathrm{PN}$ \\
\hline 8.50 & 2.10 & 1,1,3,3,5-Pentamethylcyclohexane & $\mathrm{PN}$ & 54.50 & 7.50 & 4-Methyldibenzothiophene & $2 \mathrm{~A}$ \\
\hline 9.62 & 3.02 & 1-Ethyl-2-methyl benzene & $1 \mathrm{~A}$ & 55.00 & 6.77 & 2,7-Dimethylfluorene & $2 \mathrm{~A}$ \\
\hline 10.08 & 3.11 & 1-Methyl-2-(1-methylethyl) benzene & $1 \mathrm{~A}$ & 55.58 & 7.49 & 2-Methyldibenzothiophene & $2 \mathrm{~A}$ \\
\hline 10.67 & 3.18 & 1-Methyl-3-propyl benzene & $1 \mathrm{~A}$ & 56.17 & 6.22 & 1,2,4,6,7-Pentamethylnaphthalene & $2 \mathrm{~A}$ \\
\hline 10.83 & 3.21 & 2-Methylpropyl benzene & $1 \mathrm{~A}$ & 56.58 & 7.44 & 3-Methylphenanthrene & $3 \mathrm{~A}$ \\
\hline 11.08 & 3.41 & 1-Methyl-2-(1-methylethyl) benzene & $1 \mathrm{~A}$ & 56.67 & 7.95 & 1-Methyldibenzothiophene & $2 \mathrm{~A}$ \\
\hline 11.17 & 3.12 & 2,2-Dimethylpropyl benzene & $1 \mathrm{~A}$ & 56.83 & 7.54 & 2-Methylphenanthrene & $3 \mathrm{~A}$ \\
\hline 12.00 & 3.37 & Adamantane & $\mathrm{PN}$ & 57.75 & 7.81 & 9-Methylphenanthrene & $3 \mathrm{~A}$ \\
\hline 12.00 & 3.69 & 1-Butenyl benzene & $1 \mathrm{~A}$ & 58.00 & 7.82 & 1-Methylphenanthrene & $3 \mathrm{~A}$ \\
\hline 12.83 & 3.17 & 1-Methyladamantane & $\mathrm{PN}$ & 58.08 & 2.78 & n-Nonadecane & $\mathrm{PN}$ \\
\hline 13.00 & 2.20 & n-Undecane & $\mathrm{PN}$ & 59.33 & 5.98 & 4-Ethyl dibenzothiophene & $2 \mathrm{~A}$ \\
\hline 13.08 & 3.28 & 1-Methyl-4-(2-methylpropyl)benzene & $1 \mathrm{~A}$ & 59.42 & 7.26 & 4,6-Dimetyl dibenzothiophene & $2 \mathrm{~A}$ \\
\hline 13.08 & 3.37 & 1-Methylbutylbenzene & $1 \mathrm{~A}$ & 60.17 & 7.09 & 2,4-Dimetyl dibenzothiophene & $2 \mathrm{~A}$ \\
\hline 13.25 & 3.41 & 1-Ethyl-4-(1-methylethyl)benzene & $1 \mathrm{~A}$ & 60.42 & 7.74 & 2-Phenylnaphthalene & $3 \mathrm{~A}$ \\
\hline 13.58 & 2.97 & 1,3-Dimethyl adamantane & $\mathrm{PN}$ & 60.50 & 7.23 & 2,6-Dimetyl dibenzothiophene & $2 \mathrm{~A}$ \\
\hline 18.50 & 2.43 & n-Dodecane & $\mathrm{PN}$ & 61.17 & 7.17 & 3-Ethylphenanthrene & $3 \mathrm{~A}$ \\
\hline 23.92 & 5.50 & 2-Methylnaphthalene & $2 \mathrm{~A}$ & 61.92 & 7.25 & 2-Ethylphenanthrene & $3 \mathrm{~A}$ \\
\hline 24.75 & 2.54 & n-Tridecane & $\mathrm{PN}$ & 62.00 & 7.06 & 9-Ethylphenanthrene & $3 \mathrm{~A}$ \\
\hline 24.83 & 5.78 & 1-Methylnaphthalene & $2 \mathrm{~A}$ & 62.08 & 7.60 & 3,6-Dimethylphenanthrene & $3 \mathrm{~A}$ \\
\hline 29.00 & 6.06 & 1,1'-Biphenyl & $2 \mathrm{~A}$ & 62.33 & 6.30 & 3,6-Dimetyl dibenzothiophene & $2 \mathrm{~A}$ \\
\hline 29.83 & 5.60 & 2-Ethylnaphthalene & $2 \mathrm{~A}$ & 62.33 & 7.15 & 3,5-Dimethylphenanthrene & $3 \mathrm{~A}$ \\
\hline 30.00 & 5.92 & 1-Ethylnaphthalene & $2 \mathrm{~A}$ & 62.50 & 7.26 & 2,7-Dimethylphenanthrene & $3 \mathrm{~A}$ \\
\hline 30.33 & 5.73 & Diphenylmethane & $2 \mathrm{~A}$ & 62.58 & 3.07 & 3,7-Dimetyl dibenzothiophene & $2 \mathrm{~A}$ \\
\hline
\end{tabular}


TABLe 2: Continued.

\begin{tabular}{|c|c|c|c|c|c|c|c|}
\hline${ }^{1} t_{R}$ & ${ }^{2} t_{R}$ & Compounds & Family & ${ }^{1} t_{R}$ & ${ }^{2} t_{R}$ & Compounds & Family \\
\hline 30.42 & 5.52 & 2,6-Dimethylnaphthalene & $2 \mathrm{~A}$ & 62.83 & 2.80 & n-Eicosane & $\mathrm{PN}$ \\
\hline 30.83 & 2.61 & $\mathrm{n}$-Tetradecane & $\mathrm{PN}$ & 63.17 & 7.36 & 2,10-Dimethylphenanthrene & $3 \mathrm{~A}$ \\
\hline 31.33 & 5.76 & 1,7-Dimethylnaphthalene & $2 \mathrm{~A}$ & 63.42 & 7.41 & 2,5-Dimethylphenanthrene & $3 \mathrm{~A}$ \\
\hline 31.50 & 5.82 & 1,3-Dimethylnaphthalene & $2 \mathrm{~A}$ & 63.67 & 7.54 & 1,7-Dimethylphenanthrene & $3 \mathrm{~A}$ \\
\hline 32.25 & 6.22 & 2-Methylbiphenyl & $2 \mathrm{~A}$ & 64.00 & 7.44 & 2,3-Dimethylphenanthrene & $3 \mathrm{~A}$ \\
\hline 32.42 & 5.79 & 1,4-Dimethylnaphthalene & $2 \mathrm{~A}$ & 64.17 & 7.71 & 1,9-Dimethylphenanthrene & $3 \mathrm{~A}$ \\
\hline 32.58 & 6.08 & 1,5-Dimethylnaphthalene & $2 \mathrm{~A}$ & 64.75 & 7.73 & 1,8-Dimethylphenanthrene & $3 \mathrm{~A}$ \\
\hline 33.33 & 6.11 & 1,2-Dimethylnaphthalene & $2 \mathrm{~A}$ & 65.50 & 6.91 & 1,2-Dimethylphenanthrene & $3 \mathrm{~A}$ \\
\hline 35.33 & 5.89 & 3-Methylbiphenyl & $2 \mathrm{~A}$ & 65.58 & 7.41 & 6-Methyl-2-phenylnaphthalene & $3 \mathrm{~A}$ \\
\hline 35.83 & 5.92 & 4-Methylbiphenyl & $2 \mathrm{~A}$ & 65.75 & 7.22 & 7-Methyl-2-phenylnaphthalene & $3 \mathrm{~A}$ \\
\hline 36.00 & 5.60 & $2,3^{\prime}$-Dimethylbiphenyl & $2 \mathrm{~A}$ & 66.00 & 5.86 & 1-Methyl-7-phenylnaphthalene & $3 \mathrm{~A}$ \\
\hline 36.33 & 5.44 & 2-Methyl-7-ethylnaphthalene & $2 \mathrm{~A}$ & 66.33 & 2.70 & Pyrene & $4 \mathrm{~A}$ \\
\hline 36.42 & 5.60 & 2,5-Dimethylbiphenyl & $2 \mathrm{~A}$ & 66.42 & 7.04 & 1-Methyl-3-phenylnaphthalene & $3 \mathrm{~A}$ \\
\hline 36.75 & 2.66 & n-Pentadecane & $\mathrm{PN}$ & 67.33 & 2.83 & n-Heneicosane & PN \\
\hline 36.75 & 5.66 & 2,4-Dimethylbiphenyl & $2 \mathrm{~A}$ & 68.17 & 7.01 & Trimethylphenanthrene & $3 \mathrm{~A}$ \\
\hline 36.75 & 6.58 & Dibenzofuran & $2 \mathrm{~A}$ & 71.67 & 2.88 & n-Docosane & PN \\
\hline 37.33 & 5.66 & 1-Methyl-7-ethylnaphthalene & $2 \mathrm{~A}$ & 75.83 & 2.90 & n-Tricosane & $\mathrm{PN}$ \\
\hline 37.58 & 5.55 & 1,3,7-Trimethylnaphthalene & $2 \mathrm{~A}$ & 79.83 & 2.91 & n-Tetracosane & $\mathrm{PN}$ \\
\hline 37.83 & 5.50 & 1,3,6-Trimethylnaphthalene & $2 \mathrm{~A}$ & 83.75 & 2.94 & n-Pentacosane & $\mathrm{PN}$ \\
\hline 37.92 & 6.13 & 2,3-Dimethylbiphenyl & $2 \mathrm{~A}$ & 87.42 & 2.98 & n-Hexacosane & $\mathrm{PN}$ \\
\hline 38.67 & 5.73 & 1,3,5-Trimethylnaphthalene & $2 \mathrm{~A}$ & 91.00 & 2.99 & n-Heptacosane & $\mathrm{PN}$ \\
\hline 38.83 & 5.60 & 2,3,6-Trimethylnaphthalene & $2 \mathrm{~A}$ & 94.50 & 3.02 & n-Octacosane & $\mathrm{PN}$ \\
\hline 39.75 & 5.89 & 1,2,7-Trimethylnaphthalene & $2 \mathrm{~A}$ & 97.83 & 3.06 & n-Nonacosane & $\mathrm{PN}$ \\
\hline 39.92 & 5.26 & 1,2,6-Trimethylnaphthalene & $2 \mathrm{~A}$ & 101.08 & 3.06 & n-Triacontane & $\mathrm{PN}$ \\
\hline 40.50 & 6.14 & 1,2,4-Trimethylnaphthalene & $2 \mathrm{~A}$ & 104.17 & 3.07 & n-Hentriacontane & $\mathrm{PN}$ \\
\hline 40.50 & 6.80 & Fluorene & $2 \mathrm{~A}$ & 107.17 & 3.10 & n-Dotriacontane & $\mathrm{PN}$ \\
\hline 40.58 & 5.82 & 3-Ethylbiphenyl & $2 \mathrm{~A}$ & 110.17 & 3.14 & n-Tritriacontane & $\mathrm{PN}$ \\
\hline 40.92 & 6.11 & 1,2,5-Trimethylnaphthalene & $2 \mathrm{~A}$ & 113.00 & 3.15 & $\mathrm{n}$-Tetratriacontane & $\mathrm{PN}$ \\
\hline 41.42 & 5.74 & 3,3'-Dimethylbiphenyl & $2 \mathrm{~A}$ & 115.75 & 3.22 & n-Pentatriacontane & $\mathrm{PN}$ \\
\hline 41.83 & 6.29 & 1,2,3-Trimethylnaphthalene & $2 \mathrm{~A}$ & 118.50 & 3.18 & n-Hexatriacontane & $\mathrm{PN}$ \\
\hline 41.92 & 5.81 & 3,4'-Dimethylbiphenyl & $2 \mathrm{~A}$ & 121.08 & 3.25 & n-Heptatriacontane & $\mathrm{PN}$ \\
\hline 42.25 & 5.68 & 4,4'-Dimethylbiphenyl & $2 \mathrm{~A}$ & 124.00 & 3.20 & n-Octatriacontane & $\mathrm{PN}$ \\
\hline 42.42 & 2.69 & n-Hexadecane & $\mathrm{PN}$ & 126.17 & 3.30 & $\mathrm{n}$-Nonatriacontane & $\mathrm{PN}$ \\
\hline
\end{tabular}

PN: paraffins and naphthens; 1A: monoaromatic hydrocarbon; 2A: diaromatic hydrocarbon; 3A: triaromatic hydrocarbon; and 4A: tetra-aromatic hydrocarbon.

TABLE 3: Identification of polycyclic terpanes and steranes marked in Figure 6.

\begin{tabular}{|c|c|c|c|c|c|c|c|}
\hline No. & ${ }^{1} t_{R}$ & ${ }^{2} t_{R}$ & Compounds & No. & ${ }^{1} t_{R}$ & ${ }^{2} t_{R}$ & Compounds \\
\hline 1 & 95.58 & 5.71 & $\mathrm{C}_{27} 18 \alpha$-trisnorhopane (Ts) & 23 & 88.33 & 4.37 & $\mathrm{C}_{27} 13 \beta, 17 \alpha$-20S-diacholestane \\
\hline 2 & 96.83 & 5.92 & $\mathrm{C}_{27} 17 \alpha$-trisnorhopane $(\mathrm{Tm})$ & 24 & 89.08 & 4.30 & $\mathrm{C}_{27} 13 \beta, 17 \alpha$-20R-diacholestane \\
\hline 3 & 101.42 & 5.57 & $\mathrm{C}_{29} 17 \alpha, 21 \beta$-21-ethylhopane & 25 & 89.62 & 4.32 & $\mathrm{C}_{27} 13 \alpha, 17 \beta$-20S-diacholestane \\
\hline 4 & 102.08 & 5.31 & $\mathrm{C}_{29} 18 \alpha$-30-norneohopane & 26 & 91.00 & 4.51 & $\mathrm{C}_{27} 13 \alpha, 17 \beta$-20R-diacholestane \\
\hline 5 & 102.58 & 5.55 & $\mathrm{C}_{30} 17 \alpha$-diahopane & 27 & 93.67 & 4.48 & $\mathrm{C}_{27} 5 \alpha, 14 \alpha, 17 \alpha$-20S-cholestane \\
\hline 6 & 102.92 & 5.65 & $\mathrm{C}_{29} 17 \beta, 21 \alpha$-21-ethylmoretane & 28 & 94.08 & 4.51 & $\mathrm{C}_{27} 5 \alpha, 14 \beta, 17 \beta$-20R-cholestane \\
\hline 7 & 104.08 & 5.58 & $\mathrm{C}_{30} 17 \alpha, 21 \beta$-21-isopropylhopane & 29 & 94.33 & 4.56 & $\mathrm{C}_{27} 5 \alpha, 14 \beta, 17 \beta$-20S-cholestane \\
\hline 8 & 104.67 & 5.58 & $\mathrm{C}_{30}$ pentacyclic triterpane & 30 & 95.00 & 4.61 & $\mathrm{C}_{27} 5 \alpha, 14 \alpha, 17 \alpha$-20R-cholestane \\
\hline 9 & 104.92 & 5.58 & $\mathrm{C}_{29} 17 \beta, 21 \beta$-21-ethylhopane & 31 & 95.08 & 4.59 & $\mathrm{C}_{29} 13 \beta, 17 \alpha$-20R-24-ethyldiacholestane \\
\hline 10 & 105.25 & 5.62 & $\mathrm{C}_{30} 17 \beta, 21 \alpha$-21-isopropylhopane & 32 & 95.42 & 4.56 & $\mathrm{C}_{29} 13 \alpha, 17 \beta$-20S-24-ethyldiacholestane \\
\hline 11 & 107.17 & 5.55 & $\mathrm{C}_{31} 17 \alpha, 21 \beta$-22S-21-isobutylhopane & 33 & 96.83 & 4.64 & $\mathrm{C}_{28} 5 \alpha, 14 \alpha, 17 \alpha$-20S-24-methylcholestane \\
\hline 12 & 107.50 & 5.55 & $\mathrm{C}_{31} 17 \alpha, 21 \beta-22 \mathrm{R}-21$-isobutylhopane & 34 & 97.42 & 4.67 & $\mathrm{C}_{28} 5 \alpha, 14 \beta, 17 \beta$-20R-24-methylcholestane \\
\hline 13 & 107.83 & 6.13 & Gammacerane & 35 & 97.75 & 4.64 & $\mathrm{C}_{28} 5 \alpha, 14 \beta, 17 \beta$-20S-24-methylcholestane \\
\hline 14 & 108.50 & 5.60 & $\mathrm{C}_{31} 17 \beta, 21 \alpha$-21-isobutylm & 36 & 98.58 & 4.66 & $\mathrm{C}_{28} 5 \alpha, 14 \alpha, 17 \alpha$-20R-24-methylcholestane \\
\hline 15 & 109.58 & 5.44 & $\mathrm{C}_{32} 17 \alpha, 21 \beta$-22S-21-isopentylhopane & 37 & 99.58 & 4.59 & $\mathrm{C}_{29} 5 \alpha, 14 \alpha, 17 \alpha$-20S-24-ethylcholestane \\
\hline 16 & 110.17 & 5.46 & $\mathrm{C}_{32} 17 \alpha, 21 \beta$-22R-21-isopentylhopane & 38 & 100.08 & 4.58 & $\mathrm{C}_{29} 5 \alpha, 14 \beta, 17 \beta$-20R-24-ethylcholestane \\
\hline 17 & 112.42 & 5.42 & $\mathrm{C}_{33} 17 \alpha, 21 \beta$-22S-21-isohexylhopane & 39 & 100.50 & 4.62 & $\mathrm{C}_{29} 5 \alpha, 14 \beta, 17 \beta$-20S-24-ethylcholestane \\
\hline 18 & 113.17 & 5.42 & $\mathrm{C}_{33} 17 \alpha, 21 \beta$-22R-21-isohexylhopane & 40 & 101.50 & 4.66 & $\mathrm{C}_{29} 5 \alpha, 14 \alpha, 17 \alpha$-20R-24-ethylcholestane \\
\hline 19 & 115.33 & 5.42 & $\mathrm{C}_{34} 17 \alpha, 21 \beta$-22S-21-isoheptylhopane & 41 & 102.50 & 4.58 & $\mathrm{C}_{30} 5 \alpha, 14 \alpha, 17 \alpha$-20S-4-methyl-24-ethylcholestane \\
\hline 20 & 116.25 & 5.42 & $\mathrm{C}_{34} 17 \alpha, 21 \beta$-22R-21-isoheptylhopane & 42 & 102.75 & 4.59 & $\mathrm{C}_{30} 5 \alpha, 14 \beta, 17 \beta$-20R-4-methyl-24-ethylcholestane \\
\hline 21 & 118.25 & 5.38 & $\mathrm{C}_{35} 17 \alpha, 21 \beta$-22S-21-isooctylhopane & 43 & 102.83 & 4.58 & $\mathrm{C}_{30} 5 \alpha, 14 \beta, 17 \beta$-20S-4-methyl-24-ethylcholestane \\
\hline 22 & 119.33 & 5.41 & $\mathrm{C}_{35} 17 \alpha, 21 \beta$-22R-21-isooctylhopane & 44 & 103.92 & 4.56 & $\mathrm{C}_{30} 5 \alpha, 14 \alpha, 17 \alpha$-20R-4-methyl-24-ethylcholestane \\
\hline
\end{tabular}


TABLE 4: Precisions (RSD), limits of detection (LODs), and linear ranges of the proposed method.

\begin{tabular}{lccccc}
\hline Compounds & RSD $^{\mathrm{a}}(\%)(n=5)$ & LODs $^{\mathrm{b}}(\mathrm{ng} / \mathrm{L})$ & Linear range $(\mathrm{ng} / \mathrm{L})$ & Regression equation & $r$ \\
\hline$n \mathrm{C}_{17}$-alkane & 3.6 & 0.2 & $10-800$ & $y=0.0018+0.0132 x$ & 0.9998 \\
Pristine & 5.1 & 0.5 & $10-800$ & $y=0.0105+0.0267 x$ & 0.9993 \\
Naphthalene & 7.8 & 1.6 & $10-500$ & $y=0.0237+0.0087 x$ \\
$5-\alpha$-Androstane & 4.6 & 0.8 & $10-500$ & $y=0.0138+0.0032 x$ & 0.9965 \\
\hline
\end{tabular}

${ }^{a}$ The concentration of the standard solution was $50 \mathrm{ng} / \mathrm{L}$ for each compound.

${ }^{b}$ LODs were estimated on the basis of a signal-to-noise ratio of 3 .

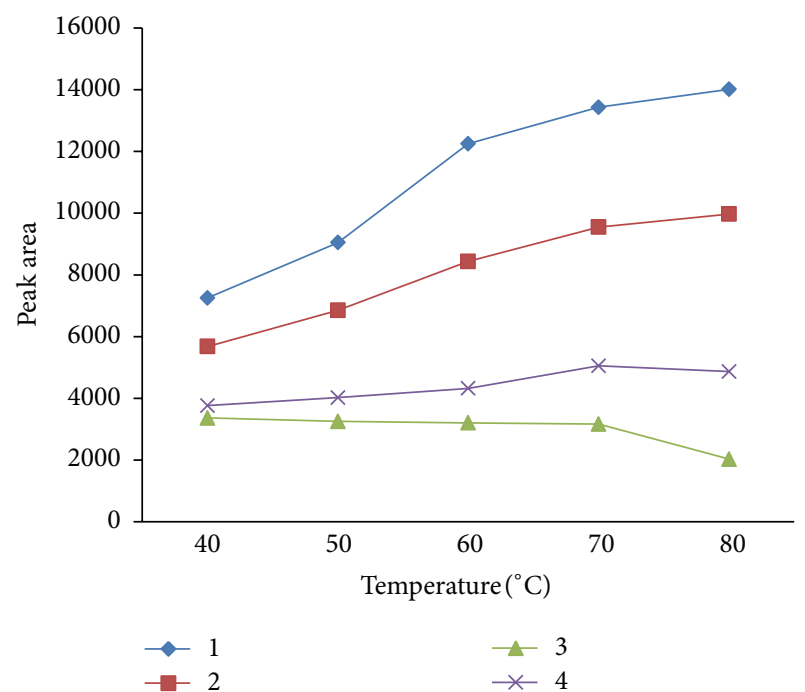

Figure 3: The extraction temperature profile for 4 representative compounds. Conditions: extraction time, $30 \mathrm{~min}$; desorption time, 5 min; saturated out with $\mathrm{NaCl}$; magnetic stirring. Peaks: $1, n \mathrm{C}_{17^{-}}$ alkane; 2, pristine; 3 , naphthalene; and 4, 5- $\alpha$-Androstane.

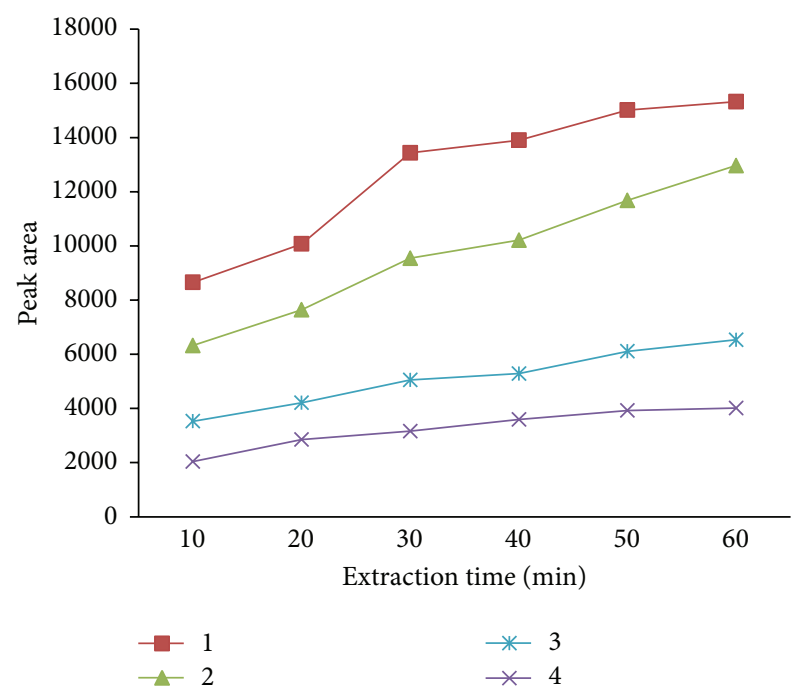

Figure 4: The extraction time profile for 4 representative compounds. Conditions: extraction temperature, $70^{\circ} \mathrm{C}$; desorption time, 5 min; saturated out with $\mathrm{NaCl}$; magnetic stirring. Peaks: $1, n \mathrm{C}_{17^{-}}$ alkane; 2, pristine; 3 , naphthalene; and 4, 5- $\alpha$-Androstane.

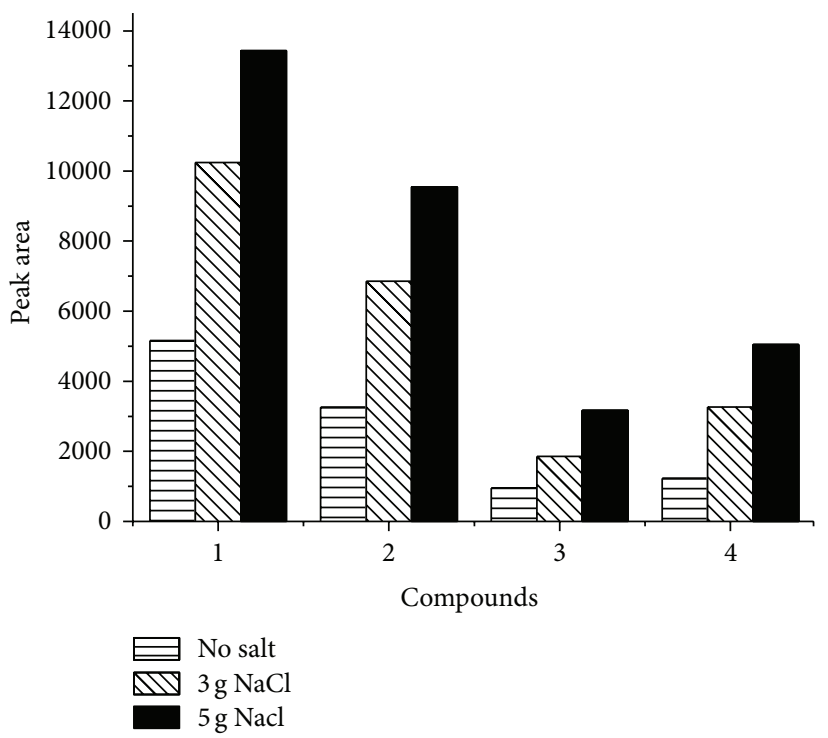

FIGURE 5: Effect of $\mathrm{NaCl}$ added on extraction. Conditions: extraction temperature, $70^{\circ} \mathrm{C}$; extraction time, $30 \mathrm{~min}$; desorption time, $5 \mathrm{~min}$; magnetic stirring. Peaks: $1, n \mathrm{C}_{17}$-alkane; 2 , pristine; 3 , naphthalene; and 4, 5- $\alpha$-Androstane.

$8 \%$, illustrating the good reproducibility of this method. Limit LODs, estimated on the basis of a signal-to-noise ratio of 3 , ranged from 0.2 to $1.6 \mathrm{ng} / \mathrm{L}$. The linearity was satisfactory, with the correlation coefficient $(r)$ over 0.996 . The linear range was from 10 to $500 \mathrm{ng} / \mathrm{L}$.

\section{Conclusions}

A sol-gel MWNTs-TSO-OH SPME fiber was prepared and coupled to $\mathrm{GC} \times \mathrm{GC} / \mathrm{TOFMS}$ for the analysis of the volatile and semivolatile organic compounds in crude oils. Compared with the commercial SPME fibers, MWNTs-TSO-OH fiber exhibited high sensitivity, thermal stability, and long lifespan. The proposed method provided a simple, efficient, and sensitive tool to simultaneously analyze the normal and branched alkanes, cycloalkanes, aromatic hydrocarbons, and biomarkers of crude oil such as steranes and terpanes. Furthermore, the method showed good linearity $(r>0.999)$, precision (RSD $<8 \%$ ), and detection limits ranging from 0.2 to $1.6 \mathrm{ng} / \mathrm{L}$. 


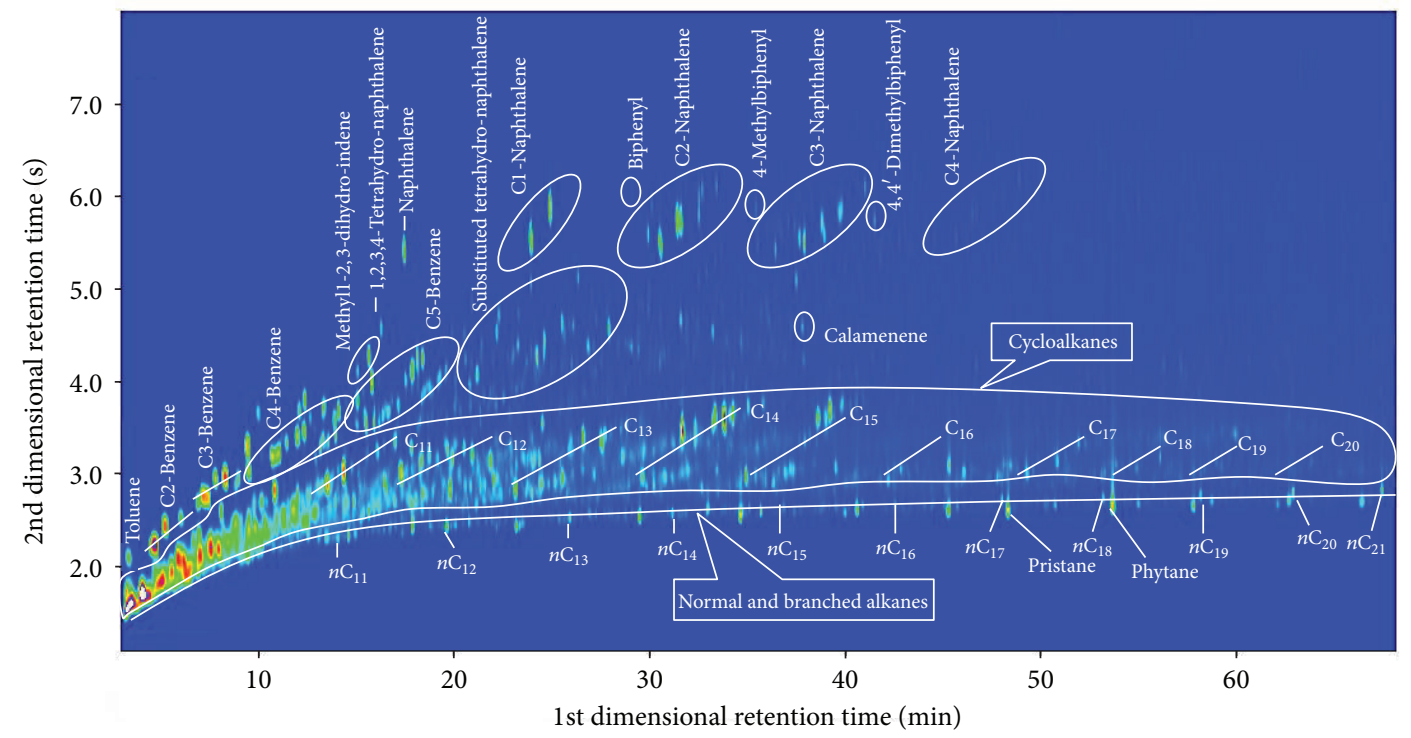

(a)

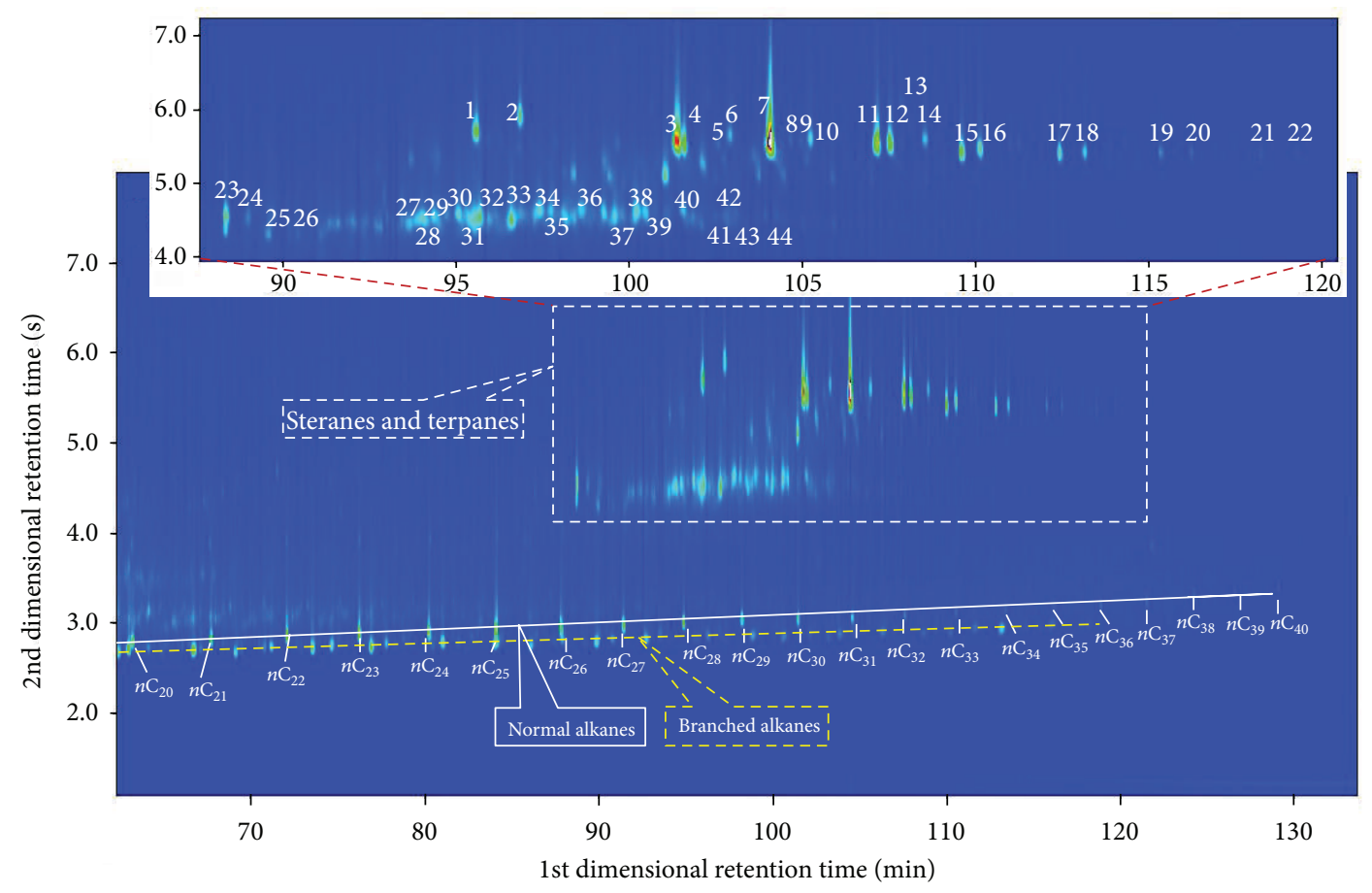

(b)

FIGURE 6: GC $\times$ GC/TOFMS total ion current chromatogram of a crude oil sample.

\section{Conflict of Interests}

All authors do not have any financial/commercial conflict of interests.

\section{Acknowledgments}

The study was supported by funding grants from the National Natural Science Foundation of China (no. 21077039), Distinguished Talents Foundation of China University of
Geosciences (no. 2011029192), and Provincial Natural Science Foundation of Hubei (no. 2009CDB325).

\section{References}

[1] K. E. Peters, C. C. Walters, and J. M. Moldowan, Eds., The Biomarker Guide: Biomarkers and Isotopes in the Environment and Human History, Cambridge University Press, New York, NY, USA, 2005. 
[2] C. Yang, Z. Wang, B. P. Hollebone, C. E. Brown, and M. Landriault, "Characteristics of bicyclic sesquiterpanes in crude oils and petroleum products," Journal of Chromatography A, vol. 1216, no. 20, pp. 4475-4484, 2009.

[3] P. A. Sutton, C. A. Lewis, and S. J. Rowland, "Isolation of individual hydrocarbons from the unresolved complex hydrocarbon mixture of a biodegraded crude oil using preparative capillary gas chromatography," Organic Geochemistry, vol. 36, no. 6, pp. 963-970, 2005.

[4] F. Jacquot, P. Doumenq, M. Guiliano, D. Munoz, J. R. Guichard, and G. Mille, "Biodegradation of the (aliphatic + aromatic) fraction of Oural crude oil. Biomarker identification using GC/MS SIM and GC/MS/MS," Talanta, vol. 43, no. 3, pp. 319330, 1996.

[5] K. D. Nizio, T. M. McGinitie, and J. J. Harynuk, "Comprehensive multidimensional separations for the analysis of petroleum," Journal of Chromatography A, vol. 1255, pp. 12-23, 2012.

[6] J. Beens, J. Blomberg, and P. J. Schoenmakers, "Proper tuning of comprehensive two-dimensional gas chromatography (GC x GC) to optimize the separation of complex oil fractions," Journal of High Resolution Chromatography, vol. 23, no. 3, pp. 182-188, 2000.

[7] M. Asif, T. Fazeelat, and K. Grice, "Petroleum geochemistry of the Potwar Basin, Pakistan: 1. Oil-oil correlation using biomarkers, $\delta^{13} \mathrm{C}$ and $\delta \mathrm{D}$," Organic Geochemistry, vol. 42, no. 10, pp. 1226-1240, 2011.

[8] C. L. Arthur and J. Pawliszyn, "Solid phase microextraction with thermal desorption using fused silica optical fibers," Analytical Chemistry, vol. 62, no. 19, pp. 2145-2148, 1990.

[9] Z. Zhang, Y. Ma, Q. Wang, A. Chen, Z. Pan, and G. Li, "Preparation of novel alumina nanowire solid-phase microextraction fiber coating for ultra-selective determination of volatile esters and alcohols from complicated food samples," Journal of Chromatography A, vol. 1290, pp. 27-35, 2013.

[10] R. S. Zhao, Y. L. Liu, X. F. Chen, J. P. Yuan, A. Y. Bai, and J. B. Zhou, "Preconcentration and determination of polybrominated diphenyl ethers in environmental water samples by solid-phase microextraction with $\mathrm{Fe}_{3} \mathrm{O}_{4}$-coated bamboo charcoal fibers prior to gas chromatography-mass spectrometry," Analytica Chimica Acta, vol. 769, pp. 65-71, 2013.

[11] D. Kim, J. Han, and Y. Choi, "On-line solid-phase microextraction of triclosan, bisphenol A, chlorophenols, and selected pharmaceuticals in environmental water samples by high-performance liquid chromatography-ultraviolet detection," Analytical and Bioanalytical Chemistry, vol. 405, pp. 377-387, 2013.

[12] S. Popiel and M. Sankowska, "Determination of chemical warfare agents and related compounds in environmental samples by solid-phase microextraction with gas chromatography," Journal of Chromatography A, vol. 1218, no. 47, pp. 8457-8479, 2011.

[13] M. A. Farag and L. A. Wessjohann, "Volatiles profiling in medicinal licorice roots using steam distillation and SolidPhase Microextraction (SPME) coupled to chemometrics," Journal of Food Science, vol. 77, no. 11, pp. C1179-C1184, 2012.

[14] N. Li, C. Deng, Y. Li, H. Ye, and X. Zhang, "Gas chromatography-mass spectrometry following microwave distillation and headspace solid-phase microextraction for fast analysis of essential oil in dry traditional Chinese medicine," Journal of Chromatography A, vol. 1133, pp. 29-34, 2006.

[15] H. Kataoka, H. L. Lord, and J. Pawliszyn, "Applications of solidphase microextraction in food analysis," Journal of Chromatography $A$, vol. 880, no. 1-2, pp. 35-62, 2000.
[16] D. Cam and S. Gagni, "Determination of petroleum hydrocarbons in contaminated soils using solid-phase microextraction with gas chromatography-mass spectrometry," Journal of Chromatographic Science, vol. 39, no. 11, pp. 481-486, 2001.

[17] B. Mokhtari and K. Pourabdollah, "SPME-GC determination of methanol as a hydrate inhibitor in crude oil," Talanta, vol. 87, no. 1, pp. 118-125, 2011.

[18] M. D’Auria, R. Racioppi, and V. Velluzzi, "A comparison of results obtained using liquid injection and headspace solidphase microextraction for crude oil analysis by GC with mass spectrometer detection," Journal of Chromatographic Science, vol. 46, no. 4, pp. 332-338, 2008.

[19] S. L. Chong, D. Wang, J. D. Hayes, B. W. Wilhite, and A. Malik, "Sol-gel coating technology for the preparation of solid-phase microextraction fibers of enhanced thermal stability," Analytical Chemistry, vol. 69, no. 19, pp. 3889-3898, 1997.

[20] S. K. Zhu, X. Lu, L. Dong et al., "Quantitative determination of compounds in tobacco essential oils by comprehensive two-dimensional gas chromatography coupled to time-of-flight mass spectrometry," Journal of Chromatography A, vol. 1086, no. 1-2, pp. 107-114, 2005.

[21] W. Zhang, Y. Sun, C. Wu, J. Xing, and J. Li, "Polymerfunctionalized single-walled carbon nanotubes as a novel sol-gel solid-phase micro-extraction coated fiber for determination of poly-brominated diphenyl ethers in water samples with gas chromatography-electron capture detection," Analytical Chemistry, vol. 81, no. 8, pp. 2912-2920, 2009.

[22] S. K. Zhu, X. Lu, Y. Q. Qiu et al., "Determination of retention indices in constant inlet pressure mode and conversion among different column temperature conditions in comprehensive two-dimensional gas chromatography," Journal of Chromatography $A$, vol. 1150, no. 1-2, pp. 28-36, 2007. 

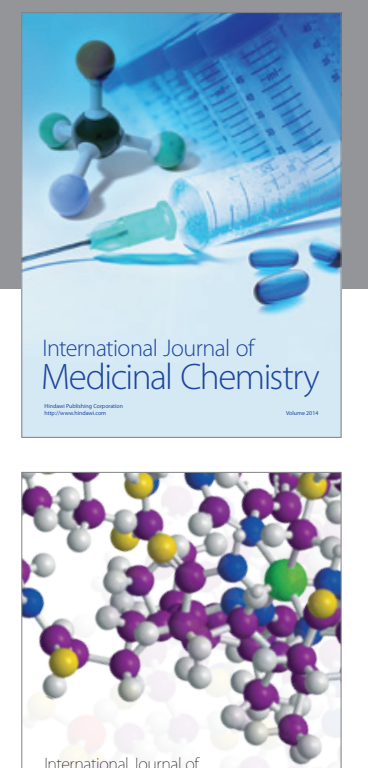

\section{Carbohydrate} Chemistry

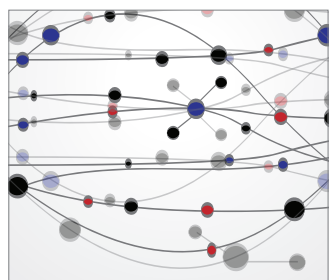

The Scientific World Journal
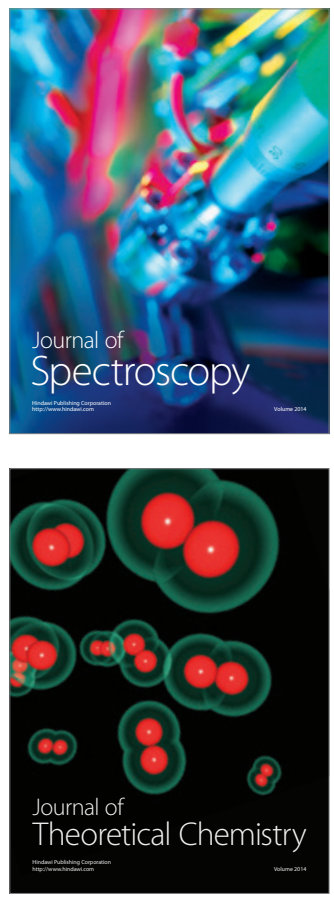
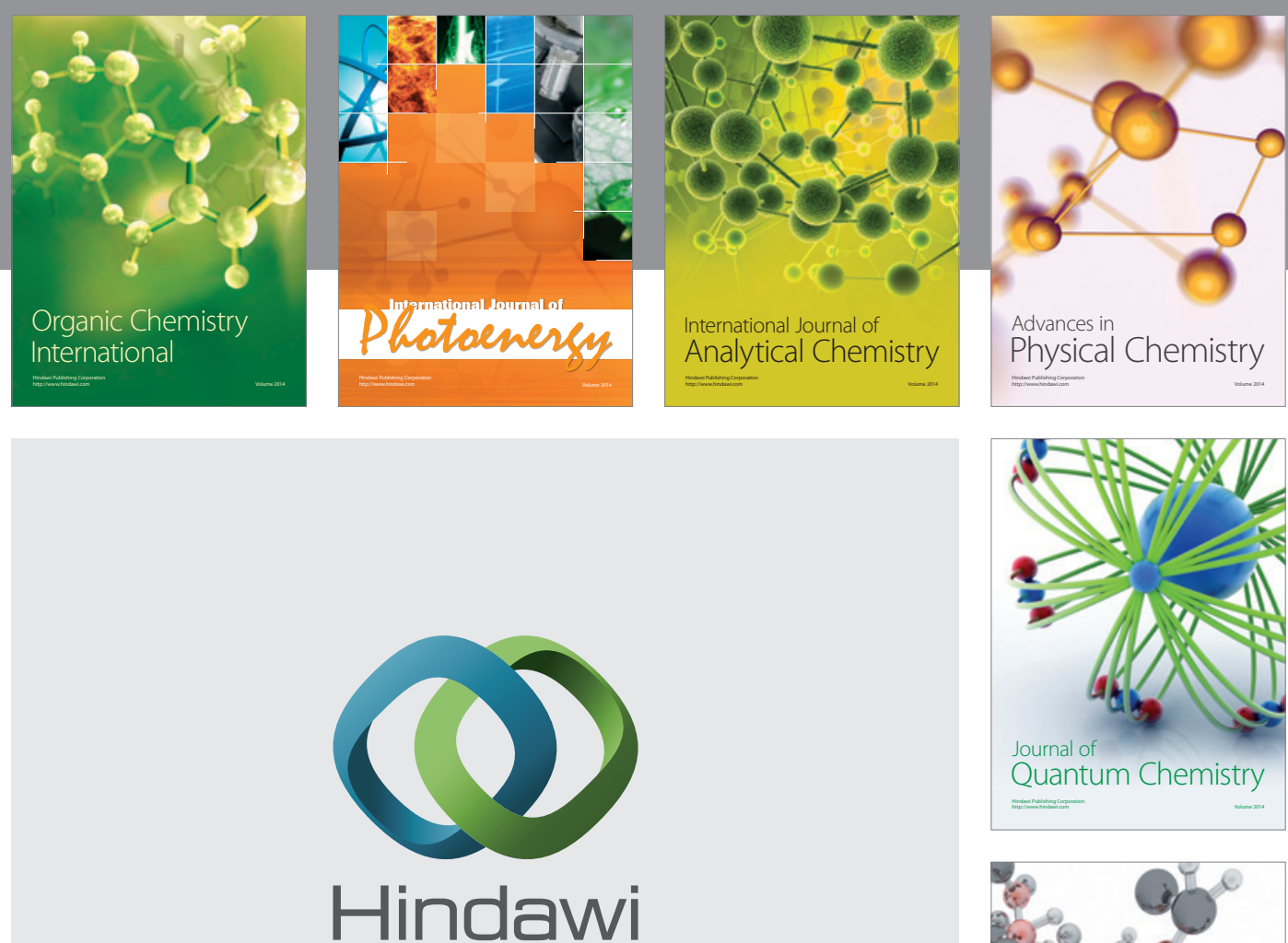

Submit your manuscripts at

http://www.hindawi.com

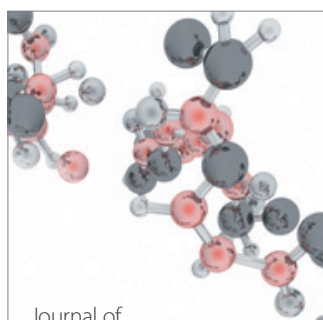

Analytical Methods

in Chemistry

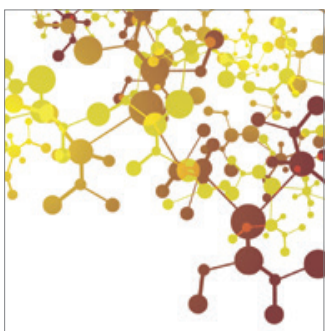

Journal of

Applied Chemistry

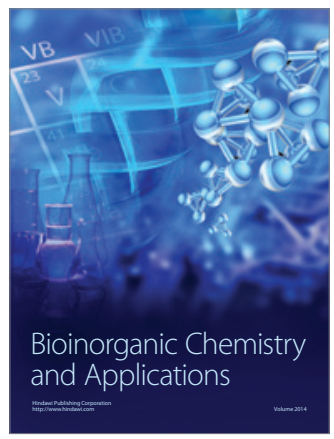

Inorganic Chemistry
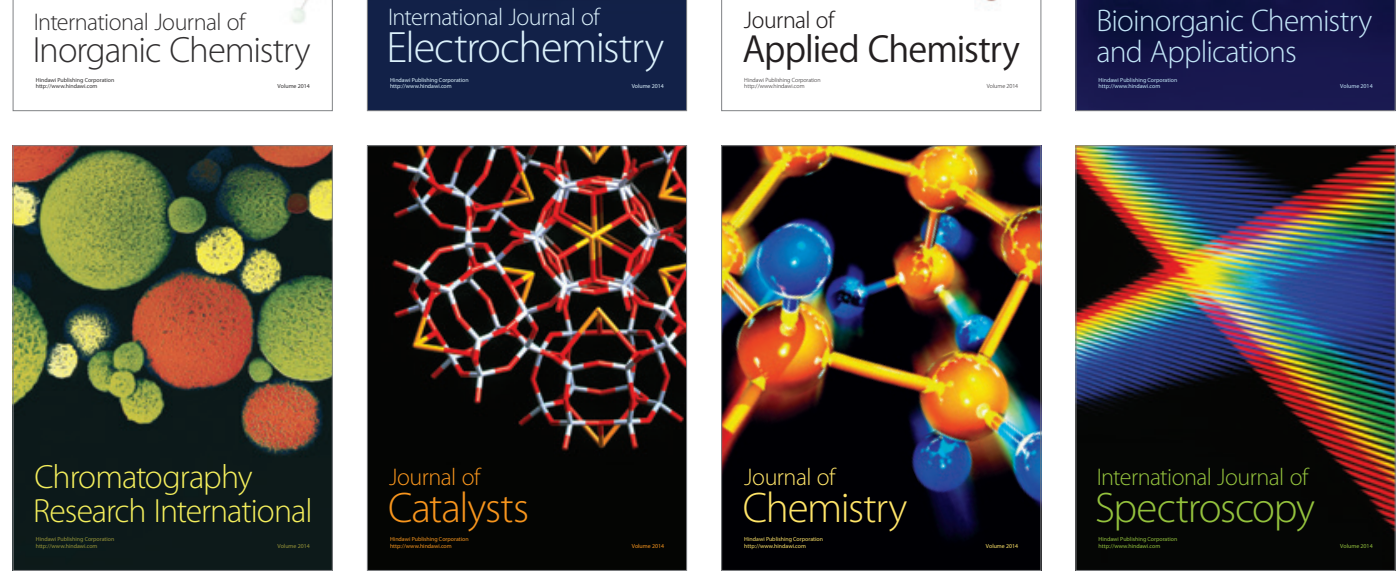